including future generations. 'In general, we would choose a population size that maximizes very broad environmental and social options for individuals', they said. 'For example the population of the United States should be small enough to permit the availability of large tracts of wilderness for hikers and hermits, yet large enough to create vibrant cities that can support complex artistic, educational, and other cultural, endeavors that lift the human spirit.'

Daily and the Ehrlichs affirmed that, as the world's present population has already exceeded 5.6 thousand millions, even if the optimum were actually 4 thousand millions, the policy implications of our conclusions are still clear.' In other words, any reasonable optimum has already been passed; thus, not only a halt to growth, but subsequent shrinkage, is required.

It will be decades before growth can be halted and shrinkage begins -- givong plentiful time to reach a consensus on what is the optimum size and where the shrinkage should be stopped.

\section{Energy Consumption Bases}

The Daily-Ehrlichs team arrived at their estimate of the optimum by 'using humanity's energy Consumption as a rough indirect measure of the total impact of civilization on Earth's life-support systems.' The use of energy - 'especially that provided by fossil fuel and biomass combustion' - directly reflects or underpins activities that cause many global environmental problems: 'Air and water pollution, acid precipitation, land degradation, emissions of carbon dioxide and other greenhouse gases, and production of toxic and hazardous materials and wastes.'

Today's technologies and total energy consumption of 13 trillion watts (13 terawatts) already cause serious environmental deterioration and are clearly not sustainable in the long run. Each American, on average, contributes almost 12,000 watts (12 kilowatts) to that total more than 10 times that of the average citizen of a poor nation.

'Suppose population growth halted at 14 thousand millions and everyone were satisfied with a per caput energy use of 7.5 kilowatts, the average in rich nations [being] about two-thirds of that in the United States in the early 1990s. A human enterprise that large would create a total impact of 105 terawatts, eight times that of today and a clear recipe for ecological collapse', the research team concluded.

The article describes energy expert John P. Holdren's optimistic scenario in which population growth stops at 10 thousand millions and both rich and poor nations converge at a level of energy-use that is less than one-third of the current American level. That level could be reached with technologies now in hand, and with an increase in the quality of life for Americans.

As the current 13-terawatts world is clearly unsustainable, 'one might postulate that, with careful choices of energy sources and technologies, 9-terawatts might be used without degrading environmental systems and dispersing non-renewable resources any more rapidly than they could be repaired or substituted for. Under similar assumptions, a 6-terawatts world would provide a 50 percent margin for error', Daily and her colleagues contended.

\section{Reduction for Sustainability}

The team considered a generous margin of error to be essential, in view of the history of unforeseen environmental threats such as the destruction to the stratospheric ozone shield. At 3 kilowatts per person, a 6-terawatts world implies 2 thousand millions of people - about the number alive in $\mathrm{AD} 1930$. That was sufficient people to allow for 'many great cities, giant industries, and thriving arts and letters. A great diversity of cultures existed, and members of many of them were not in contact with industrialized cultures. Large tracts of wilderness remained in many parts of the world... A world with 1.5 thousand million people using 4.5 terawatts of energy seems equally plausible and would carry a larger margin of safety. This is about the same number of people as existed at the turn of the century.'

PETER RAPALUS
Stanford University News Service
Press Courtyard, Santa Teresa Street
Stanford
California $94305-2245$
USA.

Peter Rapalus Press Courtyard, Santa Teresa Street California 94305-2245

USA.

\title{
Small Islands Most Vulnerable to Natural Disasters
}

$\mathrm{T}^{\mathrm{s}}$ he "sustainable development of Small Island States is considerably threatened due to their vulnerability to natural disasters and the threat of global warming which is expected to result in sea-level rise', Professor G.P. Obasi, Secretary-General of the World Meteorological Organization (WMO), told participants of the UN Conference on the Sustainable Development of Small Island Developing States which was held recently in Bridgetown, Barbados, West Indies.

Most of the world's Small Island Developing States lie in or just outside the tropics, thus making them susceptible to the ravages of tropical cyclones and other natural disasters, with often devastating results on their economies and societies. An average of 80 tropical cyclones, also known as typhoons or hurricanes, form over tropical waters every year, producing winds in excess of $120 \mathrm{~km}$ per hour and sometimes up to $300 \mathrm{~km}$ per hour in severe cases, along with associated floods and storm-surges. 'Any single event which causes a loss of life and great destruction can reverse years of development', Professor Obasi said, adding 'the high cost of reconstruction and rehabilitation, along with the escalating insurance costs, are putting considerable strains on the fragile economies of small islands which depend highly on tourism and other coastal activities'.

Efforts to reduce the impact of natural hazards are often hampered by the fact that their irregularity and uncertainty foster the notion that they do not require the urgent attention of governments, said the WMO SecretaryGeneral, adding that social and economic losses could be reduced by putting in place organized systems within the communities, to prepare for and combat their impacts: 'These systems must include long-term measures aimed at 
the provision of early-warning mechanisms and the establishment and enforcement of local preventive measures along with community education, preparedness, response, and rehabilitation'.

Statistics clearly show that, even in less-developed countries, adherence to these measures leads to a reduction of damage and loss of lives. Using as an example Hurricane David, which struck Dominica in 1979, Professor Obasi recalled the long-lasting impact that the disaster had on the island's economy, which had suffered a severe setback and a decline of $78 \%$ to $84 \%$ in GDP per caput during the ten years' period after the disaster.

WMO is involved in the activities of the current International Decade for Natural Disasters Reduction (IDNDR), which is now at its mid-decade point. 'I would hope that this Conference will bring to light the unique needs and requirements for sustainable development that can go hand in hand with the efforts which are being deployed in the context of the IDNDR towards the reduction of natural disasters globally', said the WMO Secretary-General, before outlining the following seven specific actions that could be taken by countries and the international community:

- Undertake an internationally-coordinated comprehensive risk-assessment programme to provide a standard baseline for disaster reduction;

- Strengthen the acquisition of meteorological and hydrological data, telecommunications, and data-processing infrastructures, using regionally coordinated mechanisms such as the WMO World Weather Watch and Tropical Cyclone Programmes;

- Initiate the development of prediction capabilities of other geophysical phenomena such as volcanoes and earthquakes;

- Invest in specific programmes for preparedness, including the development or improvement of hazardspecific building codes and land-use practices, public education, and warning systems;

- Participate in international programmes such as the World Climate Programme, so that specific concerns of Small Island Developing States are placed high on the priority list of studies to determine the impact of climate, its variation and change, and potential sea-level rise;

- Organize and promote specific regional technical cooperation programmes designed to assist Small Island Developing States to reduce the impacts of tropical cyclones, floods, volcanoes, earthquakes, tsunamis, and climate change including sea-level rise; and

- Develop effective public-information services, based on scientifically sound studies and analyses, in order to lead to concerted international action to promote sustainable development.

InFormation AND Public AfFairs OfFice World Meteorological Organization PO Box 2300

CH-1211 Geneva 2 Switzerland.

\section{The Significance of Urban Nature}

$\mathrm{F}^{\mathrm{r}}$ rom time to time and particularly in recent years, articles have appeared in Environmental Conservation concerning the urban environment and its resident biota, whether on urban environmental institutions (Adams, 1989); specific biota (e.g. Proulx, 1988, Fitzgerald, 1990, Jarvis, 1990, on cats; Fossi \& Renzoni, 1989, Guthová, 1993, on seagulls); urban habitat management and monitoring (Zhou et al., 1989); or the effects of urban systems on global ecology and Humankind (Ress, 1989; Shaw, 1989).

These papers and notes have conformed to the (helpfully broad) definitions of urban ecosystems proposed in 1984 by H. Sukopp, who has emphasized the social and historical aspect of increasing urbanization. Meanwhile, numerous commentators have stressed the need for integrating knowledge across the broad spectrum of disciplines involved in the urban environment, in order that true and effective environmental management can be carried out.

At the same time, various influential international bodies have published policy papers on the urban environment - including the European Commission (in 1990), the Organization for Economic Cooperation and Development (in 1990), and, most recently, the United Nations' Local Agenda 21 (see Levett, 1993). Most pertinently, Levett emphasizes (Chapter 35: Science for Sustainable Development) that 'Scientific knowledge should be applied to articulate and support the goals of sustainable development, through scientific assessments of the current conditions and future prospects for the Earth system.'
We are now at a stage where people are agreed that action is necessary to manage the urban environment, but where there are few areas of concensus on any individual issue - quite likely because of lack of scientific knowledge.

This is where (we hope) our Urban Nature Magazine comes in, for it is planned continuingly to offer a quarterly review of the latest findings regarding all manner of biota occurring in and around towns and cities. It offers commentaries (some of them controversial) and scientific papers on a variety of topics - ranging from valuing Nature in cities, to the classification of urban aquatic communities, and the importance of the urban ecocomplex overall. We would now like, through the kind hospitality of Environmental Conservation, to invite your contributions and subscriptions to Urban Nature in this, its third year of production *.

\section{REFERENCES}

ADAMs, L.W. (1989). National Institute for Urban Wildlife. Environmental Conservation, 16(3), pp. 276-7.

FitzGERALD, B.M. (1990). Is cat control needed to protect urban wildlife? Environmental Conservation, 17(2), pp. 168-9.

*We heartily support this plea, believing that such a Journal well edited and concerned also with surrounding areas from and to which plants and animals migrate - is becoming more and more needed as urbanization increases - see our book in press on Population and Global Security. As for ourselves, we have always considered urban topics as somewhat marginal for Environmental Conservation as formerly for Biological Conservation, and tend to have too much good material coming in anyway. - Ed. 